\title{
Progesterone receptor loss identifies hormone receptor-positive and HER2-negative breast cancer subgroups at higher risk of relapse: a retrospective cohort study
}

\author{
This article was published in the following Dove Press journal: \\ OncoTargets and Therapy \\ 21 March 2016 \\ Number of times this article has been viewed
}

\author{
Jia-Yuan Sun ${ }^{1, *}$ \\ San-Gang $\mathrm{Wu}^{2}{ }^{2} *$ \\ Feng-Yan $\mathrm{Li}^{\prime}$ \\ Huan-Xin Lin' \\ Zhen-Yu He'
}

'Department of Radiation Oncology, Sun Yat-sen University Cancer Center, State Key Laboratory of Oncology in South China, Collaborative Innovation Center of Cancer Medicine, Guangzhou, People's Republic of China; ${ }^{2}$ Department of Radiation Oncology, Xiamen Cancer Center, The First Affiliated Hospital of Xiamen University, Xiamen, People's Republic of China

*These authors contributed equally to this work

\begin{abstract}
Background: To assess the prognostic value of progesterone receptor (PR) expression in patients with hormone receptor-positive and human epidermal growth factor receptor 2 (HER2)negative breast cancer subgroups.
\end{abstract}

Methods: A retrospective review of breast cancer patients who underwent mastectomy or breast-conserving surgery between January 1998 and December 2007 was performed. The prognostic impact of PR status on disease-free survival (DFS) was analyzed.

Results: Of the 1,301 patients included in this study, the median follow-up time was 64 months, and the median age was 46 years. There were $18.4 \%$ of patients $(n=219)$ with PR negative $(\mathrm{PR}-)$ cancer. Women with PR- breast cancer were more likely to be postmenopausal $(P<0.001)$ and have pN3 stage $(P=0.031)$ and Stage III $(P=0.049)$ cancer. Cox regression univariate and multivariate analysis showed that PR status was a significant prognostic factor for DFS. Patients with PR - status had poorer DFS (hazard ratio $=1.626,95 \%$ confidence interval $=1.060-2.497$, $P=0.026$ ). The 5-year DFS for patients with PR- and PR+ breast cancer was $79.4 \%$ and $86.2 \%$, respectively, and the 8-year DFS for patients with PR- and PR+ breast cancer was $69.6 \%$ and $78.1 \%$, respectively $(P=0.012)$. A significant difference in DFS was observed between PRand $\mathrm{PR}+$ disease in patients with node-negative cancer, but was not for patients with lymph node metastasis $(P=0.242)$. In premenopausal patients, DFS varied significantly by PR status $(P=0.049)$. A marginally significant difference in DFS between the PR- and PR+disease was seen in postmenopausal patients (log rank $P=0.065)$.

Conclusion: Lack of PR expression is associated with worse survival in patients with hormone receptor-positive and HER2-negative breast cancer subgroups.

Keywords: breast cancer, breast cancer subtype, progesterone receptor, prognosis, recurrence

\section{Introduction}

Breast cancer can be divided into at least four subtypes based on gene expression profile; there are different breast cancer subtypes with distinct prognosis, and these subtypes can predict therapeutic efficacy. ${ }^{1-5}$ Hormone receptor-positive and human epidermal growth factor receptor 2-negative (HER2-) breast cancer subgroup is a subtype of breast cancer that is estrogen receptor-positive $(\mathrm{ER}+)$ and/or progesterone receptor-positive $(\mathrm{PR}+)$, and HER2-. Nearly 20\% of invasive breast cancers have a mixed hormone receptor status as either $\mathrm{ER}+/ \mathrm{PR}-$ or $\mathrm{ER}-/ \mathrm{PR}+\mathrm{ER}+/ \mathrm{PR}-$ is the most common mixed hormone receptor subtype. Studies have confirmed that the risk factors

\footnotetext{
Correspondence: Zhen-Yu He Yat-sen University Cancer Center, State Key Laboratory of Oncology in South China, Collaborative Innovation Center of Cancer Medicine, 65I Dongfeng East Road, Guangzhou 510060, People's Republic of China

Tel +862087343543

Fax +862087343392

Email hezhy@sysucc.org.cn
} 
associated with $\mathrm{ER}+/ \mathrm{PR}$ - breast cancer are similar to those for $\mathrm{ER}+/ \mathrm{PR}+$ disease. .,7 $^{6}$

The role of the PR in breast cancer remains controversial. While the rate of ER+ breast cancer increases with age, no such pattern is seen with the $\mathrm{PR}$, and the $\mathrm{PR}+$ rate is constant in all age-groups. ${ }^{8} \mathrm{PR}$ gene expression is dependent on estrogen, and consequently, PR expression has been considered to indicate an intact estrogen-ER response pathway. This raises the question as to whether $\mathrm{ER}+/ \mathrm{PR}$ - breast cancers are a heterogeneous disease in the hormone receptor-positive and HER2- subtype. Therefore, in this study, we evaluated the prognostic value of PR expression in hormone receptorpositive and HER2- breast cancer patients and also investigated whether it is necessary to further subtype hormone receptor-positive and HER2- breast cancer.

\section{Patients and methods}

\section{Patients}

The records of patients with breast cancer who were treated at Sun Yat-sen University Cancer Center (SYSUCC) from January 1998 to December 2007 were retrospectively analyzed. Criteria for inclusion in the analysis were: 1) females with pathologically confirmed unilateral invasive breast cancer; 2) underwent mastectomy or breast-conserving surgery, and axillary lymph node dissection; 3 ) cancer stage was T1-4N1-3M0 according to the (2009) 7th edition of the American Joint Committee on Cancer/Union for International Cancer Control Tumor-Node-Metastasis (TNM) staging system; 4) the tumor was completely resected with no positive margins; 5) complete immunohistochemistry results including ER, PR, and HER2 (patients who were ER+ and/or PR+, and HER2- were included in the analysis); and 6) corresponding therapies (chemotherapy, radiotherapy, or endocrine therapy) were given after surgery according to TNM stage and hormone receptor status. The study was approved by the Ethics Committee of SYSUCC. All patients provided written consent for storage of their medical information in the hospital database and for research use of this information.

\section{Patient characteristics and lymph node status}

Patients' clinicopathological and immunohistochemical factors, including age, menstrual status, pathologic tumor (pT) stage, pathologic node ( $\mathrm{pN}$ ) stage, ER status, PR status, Ki-67, and lymphovascular invasion were used to assess the risks of relapse. $\mathrm{ER}+$ and $\mathrm{PR}+$ were defined as $>1 \%$ positive cells on immunohistochemical staining. Breast cancer subtypes were not determined according to the criteria developed at the St Gallen
International Breast Cancer Conference, because some patients did not have immunohistochemistry testing for Ki-67. ${ }^{9}$ The expression of $\mathrm{Ki}-67$ was determined according to our previous report, and $25 \%$ positivity was used as the cutoff point. ${ }^{10}$

\section{Follow-up and survival end points}

Follow-up was performed every 3-6 months. Because all patients in this study received adjuvant treatment according to stage and hormone receptor status, the end point was disease-free survival (DFS). DFS was defined as the absence of locoregional or distant recurrence. For patients with recurrence, survival time was determined from the date of surgery to the date of locoregional recurrence and/ or distant metastasis.

\section{Statistical analysis}

All data were analyzed using the SPSS statistical software package (version 16.0; SPSS Inc., Chicago, IL, USA). The $\chi^{2}$ and Fisher's exact probability tests were used to analyze the differences between qualitative data. Survival rates were determined and plotted by the Kaplan-Meier method, and compared using the log-rank test. Univariate and multivariate Cox regression model analyses were performed. A value of $P<0.05$ was considered statistically significant.

\section{Results \\ Clinicopathological factors and relationship with PR status}

A total of 1,301 patients with hormone receptor-positive and HER2- breast cancer who met the inclusion criteria were included in this study, and their characteristics are summarized in Table 1 . The median age was 46 years (range: $21-92$ years); $66.6 \%$ of patients $(866 / 1,301)$ were premenopausal, $52.3 \%$ of patients $(681 / 1,301)$ were node-negative, and $18.4 \%$ of patients $(219 / 1,301)$ were $\mathrm{PR}-$. PR status was associated with menopausal status $(P<0.001)$, pN stage $(P=0.031)$, TNM stage $(P=0.049)$, and ER status $(P<0.001$; Table 1$)$. Women with $\mathrm{PR}$ - breast cancer were more likely to be postmenopausal and have pN3 stage and Stage III cancer.

\section{Prognosis}

Results of the univariate and multivariate analysis are listed in Table 2. In the univariate Cox analysis, age, tumor stage, node stage, TNM stage, and PR status were prognostic factors for DFS (all, $P<0.05$ ).

Multivariate Cox analysis adjusted for significant factors from the univariate analysis was used to examine DFS. Age, tumor stage, node stage, and PR status were significant 
Table I Correlation between PR and clinicopathologic characteristics

\begin{tabular}{|c|c|c|c|c|}
\hline Characteristic & N (\%) & $\begin{array}{l}\text { PR- } \\
\text { negative } \\
(\%)\end{array}$ & $\begin{array}{l}\text { PR- } \\
\text { positive } \\
(\%)\end{array}$ & $P$-value \\
\hline \multicolumn{5}{|l|}{ Age (years) } \\
\hline$\leq 35$ & $132(10.1)$ & $10(9.1)$ & $122(10.2)$ & 0.702 \\
\hline$>35$ & I,I69 (89.9) & $100(90.1)$ & I,069 (89.8) & \\
\hline \multicolumn{5}{|l|}{ Menopausal status } \\
\hline Premenopausal & $866(66.6)$ & $51(46.3)$ & $815(68.4)$ & $<0.001$ \\
\hline Postmenopausal & 435 (33.4) & $59(53.7)$ & $376(31.6)$ & \\
\hline \multicolumn{5}{|l|}{ Tumor stage } \\
\hline $\mathrm{pTI}$ & $496(38.1)$ & $38(34.5)$ & $458(38.4)$ & 0.193 \\
\hline pT2 & $703(54.0)$ & $58(52.7)$ & $645(54.2)$ & \\
\hline pT3 & $59(4.5)$ & $7(6.4)$ & $52(4.4)$ & \\
\hline pT4 & $43(3.4)$ & $7(6.4)$ & $36(3.0)$ & \\
\hline \multicolumn{5}{|l|}{ Node status } \\
\hline Negative & 681 (52.3) & $55(50.0)$ & $626(52.6)$ & 0.607 \\
\hline Positive & $620(47.7)$ & $55(50.0)$ & $565(47.4)$ & \\
\hline \multicolumn{5}{|l|}{ Nodal stage } \\
\hline pNo & $68 \mathrm{I}(52.3)$ & $55(50.0)$ & $626(52.6)$ & 0.031 \\
\hline $\mathrm{pNI}$ & $417(32.1)$ & $30(27.3)$ & $387(32.5)$ & \\
\hline $\mathrm{pN} 2$ & $113(8.7)$ & $10(9.1)$ & $103(8.6)$ & \\
\hline pN3 & $90(6.9)$ & $15(13.6)$ & $75(6.3)$ & \\
\hline \multicolumn{5}{|l|}{ TNM stage } \\
\hline I & $327(25.1)$ & $23(20.9)$ & $304(25.5)$ & 0.049 \\
\hline II & $73 \mid$ (56.2) & $57(51.8)$ & $674(56.6)$ & \\
\hline III & $243(18.7)$ & $30(27.3)$ & $213(17.9)$ & \\
\hline \multicolumn{5}{|l|}{ ER status } \\
\hline Negative & $219(16.8)$ & $0(0)$ & $219(18.4)$ & $<0.001$ \\
\hline Positive & I,082 (83.2) & $110(100)$ & $972(8 I .6)$ & \\
\hline \multicolumn{5}{|l|}{$\mathrm{Ki}-67(\mathrm{n}=834)$} \\
\hline$\leq 25 \%$ & $586(70.3)$ & $48(64.9)$ & $538(70.8)$ & 0.287 \\
\hline$>25 \%$ & $248(29.7)$ & $26(35.1)$ & $222(29.2)$ & \\
\hline \multicolumn{5}{|c|}{ Lymphovascular invasion } \\
\hline Negative & $\mathrm{I}, 264(97.2)$ & $107(97.3)$ & I,I $157(97.1)$ & 0.939 \\
\hline Positive & $37(2.8)$ & $3(2.7)$ & $34(2.9)$ & \\
\hline
\end{tabular}

Abbreviations: ER, estrogen receptor; $\mathrm{pN}$, pathologic node; PR, progesterone receptor; pT, pathologic tumor; TNM, tumor-node-metastasis.

prognostic factors for DFS (all, $P<0.05$ ). Patients with PR- disease had poorer DFS (hazard ratio $[\mathrm{HR}]=1.626$, $95 \%$ confidence interval $[\mathrm{CI}]=1.060-2.497, P=0.026)$ than patients with $\mathrm{PR}+$ disease.

\section{Relationship between PR status and survival}

The median follow-up time was 64 months (range: 6-144 months), recurrence occurred in 198 patients, and the 5- and 8-year DFS were $85.6 \%$ and $77.3 \%$, respectively. PR- status correlated with disease recurrence. The 5-year DFS for patients who were PR- and PR+ was $79.4 \%$ and $86.2 \%$, respectively; the 8 -year DFS for patients who were $\mathrm{PR}-$ and $\mathrm{PR}+$ was $69.6 \%$ and $78.1 \%$, respectively (log rank $P=0.012$; Figure 1).
The prognostic effect of PR status in patients with and without lymph node metastasis was examined. A significant difference in DFS based on PR status was observed in patients with lymph-node-negative disease; the 5-year DFS for patients with $\mathrm{PR}-$ and $\mathrm{PR}+$ disease was $81.1 \%$ and $91.8 \%$, respectively, and the 8-year DFS for patients with PR- and $\mathrm{PR}+$ disease was $75.3 \%$ and $84.9 \%$, respectively (log rank $P=0.015$; Figure 2A). However, for patients with lymph node metastasis, PR status was not associated with DFS (log rank $P=0.242$; Figure 2B).

In premenopausal patients, a significant difference in DFS based on PR status was observed; the 5-year DFS for patients with $\mathrm{PR}-$ and $\mathrm{PR}+$ disease was $75.0 \%$ and $85.6 \%$, respectively, and the 8-year DFS for patients with PR- and $\mathrm{PR}+$ disease was $70.8 \%$ and $74.8 \%$, respectively (log rank $P=0.049$; Figure 3A). A marginally significant difference in DFS between the PR- and PR+ disease was seen (5-year DFS $83.4 \%$ vs $87.6 \%$, 8 -year DFS $67.7 \%$ vs $80.7 \%$, log rank $P=0.065$; Figure 3B).

\section{Discussion}

In this study, the prognostic value of PR status was evaluated in hormone receptor-positive and HER2- breast cancer patients, and the results showed that PR status was associated with survival of patients with hormone receptor-positive and HER2- breast cancer.

The molecular biological and clinical significance of PR in hormone receptor-positive and HER2- breast cancer are still controversial. The 14th St Gallen Breast Cancer Conference defined hormone receptor-positive breast cancer as ER+ and/or PR+ cells of $>1 \% .{ }^{11}$ However, there is evidence showing that the prognosis of ER+ breast cancer patients is different between those who are PR+ and PR-.${ }^{12-15}$ Bae et al ${ }^{12}$ investigated ER+ and HER2- breast cancer patients and found that $\mathrm{PR}-$ patients had poorer DFS $(\mathrm{HR}=2.123,95 \% \mathrm{CI}=1.201-3.755, P=0.010)$ and overall survival $(\mathrm{OS})(\mathrm{HR}=4.779,95 \% \mathrm{CI}=1.874-12.189, P=0.001)$ as compared to $\mathrm{PR}+$ patients. Prat et $\mathrm{a}^{13}$ also found that luminal A breast cancer patients with $<20 \% \mathrm{PR}+$ cells had a significantly poorer prognosis when compared with those with $>20 \%$ PR+ cells. Bal et a ${ }^{14}$ found that the OS (8.7 vs 15.3 years, $P=0.032$ ) and DFS (5.7 vs 10.5 years, $P=0.022$ ) in ER+/PR-/HER2- patients were significantly shorter than in patients with ER+/PR+/HER2- breast cancer. Our results showed that $\mathrm{ER}+\mathrm{PR}$ - patients had poorer DFS as compared to $\mathrm{ER}+\mathrm{PR}+$ patients, which is consistent with the aforementioned findings. It was also found that the PR negativity was a prognostic factor in patients with luminal 
Table 2 Cox regression analysis of prognostic factors influencing the disease-free survival of breast cancer patients

\begin{tabular}{|c|c|c|c|c|c|c|}
\hline \multirow[t]{2}{*}{ Characteristic } & \multicolumn{3}{|c|}{ Univariate } & \multicolumn{3}{|c|}{ Multivariate } \\
\hline & HR & $95 \% \mathrm{Cl}$ & $P$-value & HR & $95 \% \mathrm{Cl}$ & $P$-value \\
\hline Age (continuous variable) & 0.980 & $0.967-0.994$ & 0.004 & 0.984 & $0.97 I-0.998$ & 0.022 \\
\hline \multicolumn{7}{|l|}{ Menopausal status } \\
\hline Premenopausal vs postmenopausal & 0.869 & $0.640-1.178$ & 0.364 & - & - & - \\
\hline \multicolumn{7}{|l|}{ Tumor stage } \\
\hline pT2 vs pTI & 2.211 & $1.569-3.114$ & $<0.001$ & 1.855 & $1.306-2.635$ & 0.001 \\
\hline PT3 vs PTI & 3.097 & $1.722-5.560$ & $<0.001$ & 1.944 & $1.047-3.612$ & 0.035 \\
\hline $\mathrm{pT} 4$ vs $\mathrm{pTI}$ & 3.804 & $1.964-7.367$ & $<0.001$ & 2.893 & $1.464-5.719$ & 0.002 \\
\hline \multicolumn{7}{|l|}{ Node stage } \\
\hline pNI vs pNo & 2.020 & I.459-2.797 & $<0.001$ & 1.861 & $1.34 \mid-2.583$ & $<0.001$ \\
\hline $\mathrm{pN} 2$ vs $\mathrm{pN} 0$ & 2.543 & I.607-4.024 & $<0.001$ & 1.953 & $1.213-3.144$ & 0.006 \\
\hline pN3 vs pN0 & 3.783 & $2.420-5.914$ & $<0.001$ & 2.646 & $1.653-4.234$ & $<0.001$ \\
\hline \multicolumn{7}{|l|}{ TNM stage } \\
\hline II vs I & 2.436 & $1.558-3.81 \mathrm{I}$ & $<0.001$ & 0.955 & $0.476-1.913$ & 0.896 \\
\hline III vs I & 4.214 & $2.602-6.826$ & $<0.001$ & 0.628 & $0 .|92-2.05|$ & $0.44 I$ \\
\hline \multicolumn{7}{|l|}{ ER status } \\
\hline Negative vs positive & 1.373 & $0.982-1.921$ & 0.064 & - & - & - \\
\hline \multicolumn{7}{|l|}{ PR } \\
\hline Negative vs positive & 1.700 & $1.118-2.586$ & 0.013 & 1.626 & $1.060-2.497$ & 0.026 \\
\hline \multicolumn{7}{|l|}{$\mathrm{Ki}-67$} \\
\hline$\leq 25 \%$ vs $>25 \%$ & 1.146 & $0.753-1.744$ & 0.525 & - & - & - \\
\hline \multicolumn{7}{|l|}{ Lymphovascular invasion } \\
\hline Negative vs positive & 1.518 & $0.903-2.55 I$ & 0.115 & - & - & - \\
\hline
\end{tabular}

Abbreviations: HR, hazard ratio; $\mathrm{Cl}$, confidence interval; ER, estrogen receptor; pN, pathologic node; PR, progesterone receptor; pT, pathologic tumor; TNM, tumor-nodemetastasis.

B/HER2 - breast cancer. ${ }^{16,17}$ Therefore, it is better to subtype hormone receptor-positive and HER2- breast cancer according to PR status.

Loss of the PR is associated with an activated growth factor pathway, such as for HER2, epidermal growth factor, and insulin-like growth factor-1, hypermethylation of the PR promoter, loss of heterozygosity at the PR gene locus, and resistance to tamoxifen therapy. ${ }^{18-20}$ This means

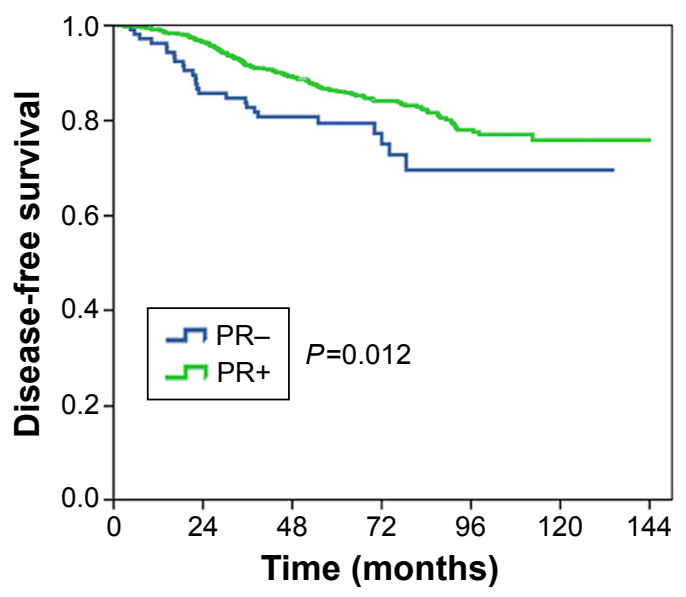

PR-patients (n) $\begin{array}{lllllll}110 & 89 & 73 & 35 & 10 & 1 & 0\end{array}$

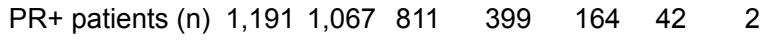

Figure I Kaplan-Meier plot of disease-free survival by PR status. Abbreviation: PR, progesterone receptor. that $\mathrm{ER}+\mathrm{PR}$ - breast cancer exhibits a more aggressive phenotype. Patients with ER+/PR- tumors had a higher recurrence rate in the tamoxifen and combination arm of the ATAC (Arimidex, Tamoxifen Alone or in Combination) trial, but recurrence rates were similar in both $\mathrm{ER}+\mathrm{PR}+$ and $\mathrm{ER}+/$ PR- tumors that had only been treated with anastrozole. ${ }^{21}$ This was because of the diminished efficiency of tamoxifen in $\mathrm{PR}$ - subgroup. Yu et al ${ }^{18}$ found that in $\mathrm{ER}+\mathrm{PR}$ - breast cancer patients, the risk of recurrence in patients treated with aromatase inhibitors was lower than in those treated with tamoxifen. ${ }^{22}$

In our study, most of the PR- breast cancer patients were postmenopausal, which is consistent with previous reports. ${ }^{14,23}$ This is a result of ovarian shutdown in the elderly, which causes insufficient levels of estrogen to transcribe PRs. ${ }^{19}$ Thus, we further evaluated whether the PR status affected the prognosis of breast cancer patients with different menopausal status. The results indicated that PR- premenopausal patients had a poorer prognosis, and a negative PR status was also detrimental to the prognosis of postmenstrual patients. Nishimukai et $\mathrm{a}^{23}$ also found that postmenstrual patients with a low PR expression $(<20 \%)$ had marginally significant differences in distant relapse-free survival compared to patients with higher PR expression $(P=0.060)$. These findings suggest that PR status not only 

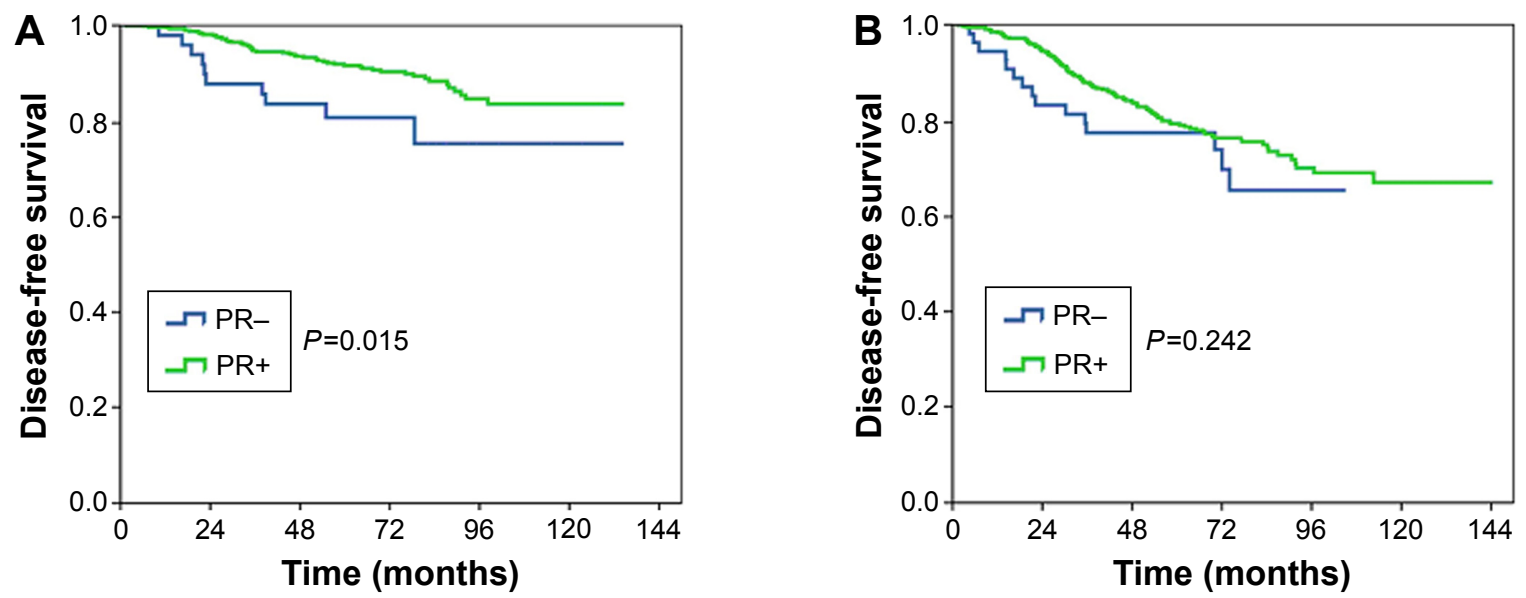

\begin{tabular}{|c|c|c|c|c|}
\hline PR-patients (n) 55 & 44 & 39 & 17 & 4 \\
\hline PR+ patients (n) 626 & 570 & 476 & 233 & 92 \\
\hline
\end{tabular}

$\begin{array}{llllllll}\text { PR- patients }(n) & 55 & 45 & 34 & 18 & 6 & 0 & 0 \\ \text { PR+ patients }(n) & 565 & 497 & 335 & 166 & 72 & 20 & 2\end{array}$

Figure 2 Kaplan-Meier plot of disease-free survival by PR status in (A) lymph-node-negative patients and (B) lymph-node-positive patients. Abbreviation: PR, progesterone receptor.

affects the efficacy of endocrine therapy in postmenstrual patients but also has prognostic value in premenopausal patients. Thus, clinicians should emphasize PR status in both pre- and postmenopausal patients, because PR status is able to not only predict prognosis but is also useful for guiding the selection of adjuvant therapy.

Whether lymph node status affects the prognostic value of PR status in breast cancer patients is still controversial. There is evidence showing that $\mathrm{PR}-$ patients have a higher risk for lymph node metastasis..$^{14,24}$ However, our results showed that PR status had no relationship with nodal status, but with the number of lymph node metastasis (pN3 stage).
Further analysis showed the PR status only affected the survival of patients without lymph node metastasis and had no influence on the prognosis of patients with positive lymph nodes. However, a study by Park et $\mathrm{al}^{24}$ revealed that PR status affected the prognosis of luminal A breast cancer patients with positive lymph nodes, but failed to influence the prognosis of lymph-node-negative patients. Purdie et $\mathrm{a}^{25}$ found that PR expression in primary breast cancer was strongly and independently associated with worse prognosis in all subgroups, including ER+/lymphnode-negative patients; however, the study did not further evaluate HER2 status. ${ }^{25}$
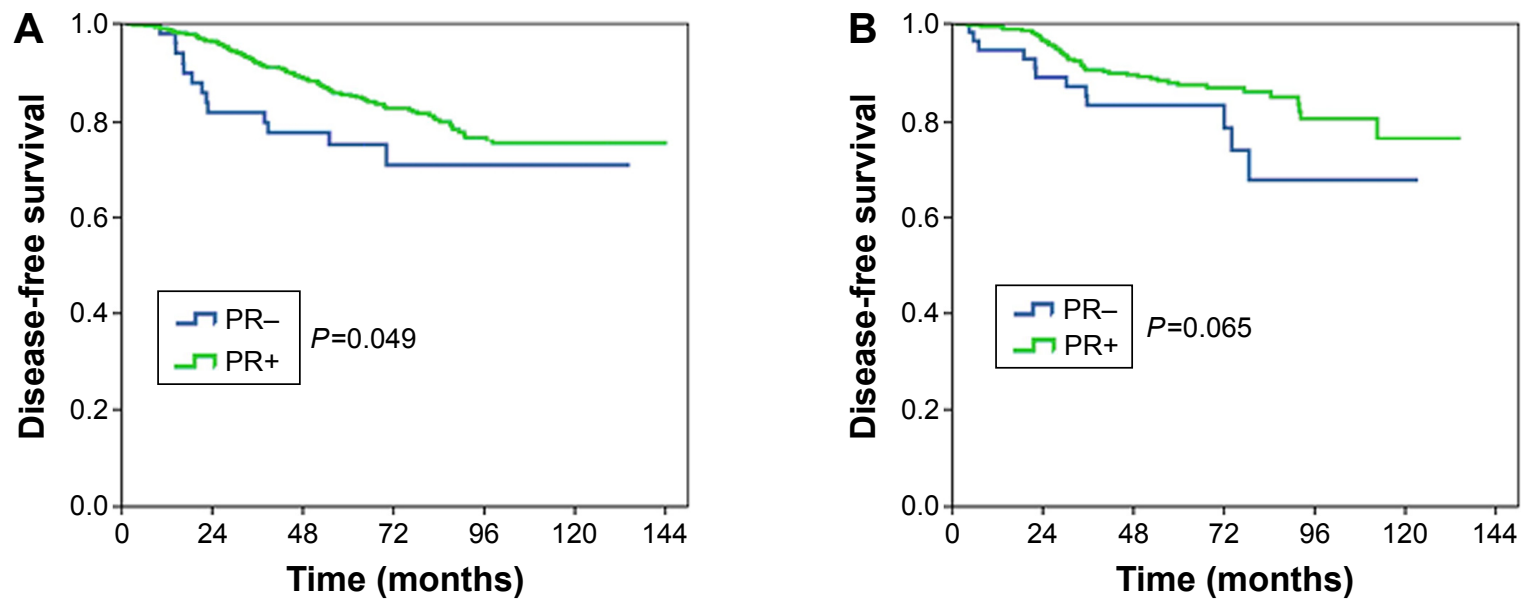

$\begin{array}{lllllll}\text { PR- patients }(\mathrm{n}) \mathrm{51} & 41 & 34 & 17 & 7 & 1 & 0 \\ \text { PR+ patients }(\mathrm{n}) \mathrm{815} & 734 & 556 & 273 & 112 & 28 & 1\end{array}$

$\begin{array}{llllll}\text { PR- patients }(\mathrm{n}) 59 & 48 & 39 & 18 & 3 & 1 \\ \text { PR+ patients }(\mathrm{n}) 376 & 333 & 255 & 126 & 52 & 14\end{array}$

Figure 3 Kaplan-Meier plot of disease-free survival by PR status in (A) premenopausal patients and (B) postmenopausal patients. Abbreviation: PR, progesterone receptor. 
There are a few limitations of this study. First, this was a single-center retrospective study, and the results might not extend to all breast cancer patients. Second, we did not stratify patients according to treatment with tamoxifen or aromatase inhibitors. In addition, this study spans a 10-year period, and thus there may be some methodological problems with ER/PR assessment.

\section{Conclusion}

Our findings suggest that lack of PR expression is associated with worse survival in hormone receptor-positive and HER2- breast cancer patients. We recommend further subdividing hormone receptor-positive and HER2- breast cancer subgroups according to PR status, which may be helpful to predict prognosis and guide treatment selection. Further prospective trials and larger studies are needed to confirm the aforementioned results and to better define subgroups of patients with hormone receptor-positive and HER2- breast cancer.

\section{Acknowledgments}

This work was supported by grants from the National Natural Science Foundation of China (number 81402527), the Sci-Tech Office of Guangdong Province (number 2013B021800157), the Youth Foundation of Fujian Provincial Health and Family Planning Commission (number 2014-2-63), and the Natural Science Foundation of Fujian Province (number 2015J01550).

\section{Disclosure}

The authors report no conflicts of interest in this work.

\section{References}

1. Sørlie T, Perou CM, Tibshirani R, et al. Gene expression patterns of breast carcinomas distinguish tumor subclasses with clinical implications. Proc Natl Acad Sci U S A. 2001;98(19):10869-10874.

2. Carey LA, Perou CM, Livasy CA, et al. Race, breast cancer subtypes, and survival in the Carolina Breast Cancer Study. JAMA. 2006; 295(21):2492-2502.

3. Martín M, Rodríguez-Lescure A, Ruiz A, et al. Molecular predictors of efficacy of adjuvant weekly paclitaxel in early breast cancer. Breast Cancer Res Treat. 2010;123(1):149-157.

4. Hugh J, Hanson J, Cheang MC, et al. Breast cancer subtypes and response to docetaxel in node-positive breast cancer: use of an immunohistochemical definition in the BCIRG 001 trial. J Clin Oncol. 2009; 27(8):1168-1176.

5. Wu SG, He ZY, Li Q, et al. Predictive value of breast cancer molecular subtypes in Chinese patients with four or more positive nodes after postmastectomy radiotherapy. Breast. 2012;21(5):657-661.

6. Dunnwald LK, Rossing MA, Li CI. Hormone receptor status, tumor characteristics, and prognosis: a prospective cohort of breast cancer patients. Breast Cancer Res. 2007;9(1):R6.
7. Colditz GA, Rosner BA, Chen WY, Holmes MD, Hankinson SE. Risk factors for breast cancer according to estrogen and progesterone receptor status. J Natl Cancer Inst. 2004;96(3):218-228.

8. Yip $\mathrm{CH}$, Rhodes A. Estrogen and progesterone receptors in breast cancer. Future Oncol. 2014;10(14):2293-2301.

9. Goldhirsch A, Winer EP, Coates AS, et al. Personalizing the treatment of women with early breast cancer: highlights of the St Gallen International Expert Consensus on the Primary Therapy of Early Breast Cancer 2013. Ann Oncol. 2013;24(9):2206-2223.

10. Li FY, Wu SG, Zhou J, et al. Prognostic value of Ki-67 in breast cancer patients with positive axillary lymph nodes: a retrospective cohort study. PLoS One. 2014;9(2):e87264.

11. Coates AS, Winer EP, Goldhirsch A, et al. Tailoring therapies improving the management of early breast cancer: St Gallen International Expert Consensus on the Primary Therapy of Early Breast Cancer 2015. Ann Oncol. 2015;26(8):1533-1546.

12. Bae SY, Kim S, Lee JH, et al. Poor prognosis of single hormone receptor-positive breast cancer: similar outcome as triple-negative breast cancer. BMC Cancer. 2015;15:138.

13. Prat A, Cheang MC, Martín M, et al. Prognostic significance of progesterone receptor-positive tumor cells within immunohistochemically defined luminal A breast cancer. J Clin Oncol. 2013;31(2):203-209.

14. Bal O, Yalcintas Arslan U, Durnali A, et al. Progesterone receptor status in determining the prognosis of estrogen receptor positive/HER2 negative breast carcinoma patients. $J$ BUON. 2015;20(1):28-34

15. Feeley LP, Mulligan AM, Pinnaduwage D, et al. Distinguishing luminal breast cancer subtypes by Ki67, progesterone receptor or TP53 status provides prognostic information. Mod Pathol. 2014;27(4):554-561.

16. Zong Y, Zhu L, Wu J, et al. Progesterone receptor status and Ki-67 index may predict early relapse in luminal B/HER2 negative breast cancer patients: a retrospective study. PLoS One. 2014;9(8):e95629.

17. Cancello G, Maisonneuve P, Rotmensz N, et al. Progesterone receptor loss identifies luminal B breast cancer subgroups at higher risk of relapse. Ann Oncol. 2013;24(3):661-668.

18. Cui X, Schiff R, Arpino G, Osborne CK, Lee AV. Biology of progesterone receptor loss in breast cancer and its implications for endocrine therapy. J Clin Oncol. 2005;23(30):7721-7735.

19. Thakkar JP, Mehta DG. A review of an unfavorable subset of breast cancer: estrogen receptor positive progesterone receptor negative. Oncologist. 2011;16(3):276-285.

20. Arpino G, Weiss H, Lee AV, et al. Estrogen receptor-positive, progesterone receptor-negative breast cancer: association with growth factor receptor expression and tamoxifen resistance. J Natl Cancer Inst. 2005; 97(17):1254-1261

21. Baum M, Buzdar A, Cuzick J, et al. Anastrozole alone or in combination with tamoxifen versus tamoxifen alone for adjuvant treatment of postmenopausal women with early-stage breast cancer: results of the ATAC (arimidex, tamoxifen alone or in combination) trial efficacy and safety update analyses. Cancer. 2003;98(9):1802-1810.

22. Yu KD, Liu GY, Di GH, et al. Progesterone receptor status provides predictive value for adjuvant endocrine therapy in older estrogen receptor-positive breast cancer patients. Breast. 2007;16(3):307-315.

23. Nishimukai A, Yagi T, Yanai A, et al. High Ki-67 expression and low progesterone receptor expression could independently lead to a worse prognosis for postmenopausal patients with estrogen receptor-positive and HER2-negative breast cancer. Clin Breast Cancer. 2015;15(3): 204-211.

24. Park S, Park BW, Kim TH, et al. Lack of either estrogen or progesterone receptor expression is associated with poor survival outcome among luminal A breast cancer subtype. Ann Surg Oncol. 2013;20(5): $1505-1513$.

25. Purdie CA, Quinlan P, Jordan LB, et al. Progesterone receptor expression is an independent prognostic variable in early breast cancer: a population-based study. Br J Cancer. 2014;110(3):565-572. 


\section{Publish your work in this journal}

OncoTargets and Therapy is an international, peer-reviewed, open access journal focusing on the pathological basis of all cancers, potential targets for therapy and treatment protocols employed to improve the management of cancer patients. The journal also focuses on the impact of management programs and new therapeutic agents and protocols on
Dovepress

patient perspectives such as quality of life, adherence and satisfaction. The manuscript management system is completely online and includes a very quick and fair peer-review system, which is all easy to use. Visit http://www.dovepress.com/testimonials.php to read real quotes from published authors.

Submit your manuscript here: http://www.dovepress.com/oncotargets-and-therapy-journal 